\title{
Paramagnetic $\mathrm{Cu}$ (II) For Probing Membrane Protein Structure and Function: Inhibition Mechanism of the Influenza M2 Proton Channel
}

\author{
Yongchao Su, Fanghao Hu, and Mei Hong* \\ Department of Chemistry, lowa State University, Ames, IA 50011
}

\section{Abstract}

Paramagnetic $\mathrm{Cu}(\mathrm{II})$ ions enhance nuclear spin relaxation in a distance-dependent fashion and can be used as a structural probe of proteins. $\mathrm{Cu}$ (II) can also serve as functionally important ligands in proteins. Here we investigate the structural basis of $\mathrm{Cu}(\mathrm{II})$ inhibition of the influenza $\mathrm{M} 2$ proton channel through $\mathrm{Cu}(\mathrm{II})$-induced paramagnetic relaxation enhancement (PRE). ${ }^{13} \mathrm{C} \mathrm{T}_{1}$ relaxation rates of the central residues of the transmembrane (TM) domain of M2 are significantly enhanced by $\mathrm{Cu}(\mathrm{II})$, and pronounced spectral broadening is observed for the proton-selective residue, His 37 . These data yielded quantitative distances of ${ }^{13} \mathrm{C}$ spins to the $\mathrm{Cu}(\mathrm{II})$ center, and identified the $\mathrm{Cu}(\mathrm{II})$ binding site to be $\mathrm{Ne} 2$ of His37. This binding site is surrounded by four imidazole rings from the top and four indole rings of Trp41 from the bottom, thus explaining the high affinity of $\mathrm{Cu}$ (II) binding. Bound at this location, $\mathrm{Cu}$ (II) can inhibit proton currents by perturbing histidinewater proton exchange, preventing histidine conformational dynamics, and interfering with HisTrp cation- $\pi$ interaction. The $\mathrm{Cu}(\mathrm{II})$ binding site is distinct from the binding site of the hydrophobic drug amantadine, which is about $10 \AA \mathrm{N}$-terminal to His37. Consistently, $\mathrm{Cu}$ (II) and amantadine induce distinct conformational changes at several key residues, suggesting the possibility of designing new drugs that target the His37 site to inhibit amantadine-resistant mutant M2 proteins. In addition to the high-affinity His37 binding site, we also examined the weaker and non-specific binding of $\mathrm{Cu}$ (II) to membrane-surface lipid phosphates and the extent of the resulting PRE to surface-proximal protein residues. This study demonstrates the feasibility of NMR studies of paramagnetic-ion complexed membrane proteins, where the ion serves as both a functional ligand and a distance probe.

\section{Introduction}

Structure determination of membrane proteins by magic-angle-spinning (MAS) solid-state NMR requires not only local structural constraints such as torsion angles and short-range distances ${ }^{1-3}$, but also long distances (above $5 \AA$ ) to constrain the protein three-dimensional fold. These long-range distances are more difficult to measure than short-range ones because of the weakness of internuclear dipolar couplings for ${ }^{13} \mathrm{C}$ and ${ }^{15} \mathrm{~N}$ nuclei and the complexity of measuring ${ }^{1} \mathrm{H}-{ }^{1} \mathrm{H}$ dipolar couplings in organic solids. In ${ }^{13} \mathrm{C}$ and ${ }^{15} \mathrm{~N} 2 \mathrm{D}$ correlation spectra, cross peaks for distances above $5 \AA$ require long mixing times to observe ${ }^{4}$ and thus are limited by nuclear spin relaxation. Even when long-range cross peaks are present, they are usually dominated by high-intensity cross peaks from nuclei within an amino acid residue ${ }^{5}$. Although techniques for measuring ${ }^{1} \mathrm{H}$ distances to ${ }^{13} \mathrm{C}$ or ${ }^{15} \mathrm{~N}^{6}$ and ${ }^{19} \mathrm{~F}-{ }^{19} \mathrm{~F}$ distances ${ }^{7,8}$ have been developed to increase the distance upper limit of NMR, these

Corresponding author: Mei Hong, Tel: 515-294-3521, Fax: 515-294-0105, mhong@ iastate.edu.

Supporting Information Available

Additional tables and NMR spectra are provided. This information is available free of charge via the Internet at http://pubs.acs.org/. 
techniques require site-specific labels, thus do not easily yield many distances simultaneously.

Paramagnetic relaxation enhancement (PRE) is an effective way to measure long-range distances. The unpaired electrons in paramagnetic metal ions enhance longitudinal $\left(\mathrm{T}_{1}\right)$ and transverse $\left(\mathrm{T}_{2}\right)$ relaxation of nuclear spins according to the inverse sixth power of the electron-nucleus distance ${ }^{9}$. Because PRE scales with the electron gyromagnetic ratio, which is two to three orders of magnitude larger than the gyromagnetic ratios of nuclear spins, distances up to $\sim 20 \AA$ can be measured using this effect ${ }^{10}$. For paramagnetic ions with high numbers of unpaired electrons and long (nanosecond to microsecond) electron spin relaxation times, transverse PRE dominates, which broadens the lineshapes and quenches the signals in the NMR spectra. In comparison, paramagnetic ions with small numbers of unpaired electrons and short electron-spin relaxation times causes smaller transverse PRE, which allows longitudinal PRE to be detected in unbroadened spectra to quantify the electron-nucleus distances. In addition to PRE, paramagnetic ions cause distance-dependent dipolar hyperfine shifts, also called pseudocontact shifts (PCS) ${ }^{11,12}$. This effect has been exploited in small molecules ${ }^{13,14}$ as well as metalloproteins ${ }^{15,16}$ under fast MAS.

$\mathrm{Cu}$ (II) is an especially favorable paramagnetic ion for structure determination by PRE, because it has relatively short electron spin relaxation times and small $g$-tensor anisotropy, thus causing moderate line broadening and small isotropic PCS, respectively. As a result, $\mathrm{Cu}$ (II)-induced $\mathrm{T}_{1}$ and $\mathrm{T}_{2}$ PRE can be measured readily, and has been used to determine the global fold of microcrystalline proteins ${ }^{10,17}$ and $\mathrm{Cu}$ (II) binding sites in amyloid fibrils ${ }^{18}$.

For membrane-bound proteins, paramagnetic ions have so far been mainly used to measure the depth of protein residues from the membrane surface where the metal ions bind ${ }^{1}$. Both lanthanides such as Gd(III), Dy(III) and Pr(III) and non-lanthanides such as Mn(II) have been employed for this purpose, and pseudocontact shifts ${ }^{19}$ and $\mathrm{T}_{2}$ PRE ${ }^{20-22}$ were observed. In addition, $\mathrm{Cu}$-chelated lipids have been employed to enhance the sensitivity of membrane protein NMR ${ }^{23,24}$. However, $\mathrm{Cu}$ (II) has not been used to investigate the structure of membrane proteins, whether through its non-specific binding to the membrane surface or through site-specific binding to protein sidechains. Compared to globular and fibrous proteins, hydrated lipid membranes present additional complexity for $\mathrm{Cu}(\mathrm{II}) \mathrm{PRE}$, since $\mathrm{Cu}(\mathrm{II})$ can bind lipid phosphates, buffer ions and hydroxide ions in water, in addition to specific protein sites. Therefore, distance determination of membrane proteins using $\mathrm{Cu}(\mathrm{II}) \mathrm{PRE}$ requires careful consideration of multiple binding equilibria.

The influenza M2 protein forms a tetrameric proton channel in the virus envelope that acidifies the virion to initiate virus uncoating ${ }^{25-28}$. Proton selectivity is achieved by a single histidine in the transmembrane (TM) domain, His37 ${ }^{29}$, whereas channel gating is accomplished by Trp41 30 , one helical turn away from His37. The channel is inhibited by the adamantane class of antiviral drugs 31,32 and by $\mathrm{Cu}(\mathrm{II})^{33}$. Whole-cell electrophysiology experiments indicated that $\mathrm{Cu}(\mathrm{II})$ inhibition was biphasic: a low-affinity binding site exists outside the TM electric field with an equilibrium dissociation constant $\left(\mathrm{K}_{\mathrm{D}}\right)$ of $\sim 100 \mu \mathrm{M}$, while a high-affinity binding site with a $\mathrm{K}_{\mathrm{D}}$ of $\sim 2 \mu \mathrm{M}$ exists in the TM electric field. Highaffinity $\mathrm{Cu}$ (II) binding is sensitive to $\mathrm{pH}$ and applied voltage, and $\mathrm{Cu}(\mathrm{II})$ inhibits both inward and outward currents. Prior application of the hydrophobic drug BL-1743 prevented $\mathrm{Cu}$ (II) inhibition, indicating competitive binding ${ }^{33}$. These biochemical data suggested His37 to be the high-affinity $\mathrm{Cu}(\mathrm{II})$ binding site; however, no structural data has been reported to determine the exact position of $\mathrm{Cu}$ (II). An atomic-level structural study of $\mathrm{Cu}$ (II) binding to M2TM will be useful for understanding the $\mathrm{Cu}$ (II) inhibition mechanism in comparison with the inhibition mechanism of hydrophobic drugs. 
In this study, we investigate the $\mathrm{Cu}$ (II) binding site in the M2 TM domain (M2TM) using ${ }^{13} \mathrm{C}$ PRE. We show that high-affinity $\mathrm{Cu}$ (II) binding to M2TM is achieved under appropriate $\mathrm{pH}$ and solution conditions where the competing binding equilibria are minimized. Based on spectral line broadening, ${ }^{13} \mathrm{C} \mathrm{T}_{1}$ PRE and the resulting distances, we have identified the high-affinity binding site and also propose the low-affinity site detected in the electrophysiology experiments. Our results indicate that the $\mathrm{Cu}(\mathrm{II})$ inhibition mechanism is distinct from the amantadine inhibition mechanism, and demonstrate that $\mathrm{Cu}$ (II) PRE is a useful and general probe of membrane protein structure and function.

\section{Materials and Methods}

\section{Membrane sample preparation}

All lipids, including 1-palmitoyl-2-oleoyl-sn-glycero-3-phosphocholine (POPC), 1palmitoyl-2-oleoyl-sn-glycero-3-phosphoethanolamine (POPE), egg sphingomyelin (SM), and cholesterol (Chol), were obtained from Avanti Polar Lipids (Alabaster, AL). The transmembrane domain (residues 22-46) of the M2 protein of the Udorn strain of influenza A virus was synthesized by PrimmBiotech (Cambridge, MA) using Fmoc chemistry and purified to $>95 \%$ purity. The amino acid sequence is SSDPLVVAASIIGILHLILWILDRL. Three site-specifically labeled peptides were used in this work, with ${ }^{13} \mathrm{C},{ }^{15} \mathrm{~N}$-labeled residues at Val28, Ser31, Ile32 and Leu36 (VSIL-M2TM), Gly34, His37 and Ile39 (GHIM2TM) and Leu40 and Trp41 (LW-M2TM).

M2TM was reconstituted into a virus-envelope-mimetic membrane (termed VM+) consisting of POPC: POPE: SM: Chol at a molar ratio of 5: 5: 5: 4.5 ${ }^{34,35}$. The lipids were codissolved in chloroform and methanol, dried under nitrogen gas and lyophilized overnight. The homogeneous lipid powder was suspended in $1 \mathrm{~mL}$ of $\mathrm{pH} 4.5$ water, vortexed, and subject to eight cycles of freeze-thawing to create uniform vesicles. No buffer was used in preparing these membrane samples because many common buffer ions such as phosphates and Tris form insoluble complexes with $\mathrm{Cu}(\mathrm{II}){ }^{36,37}$, which deplete free $\mathrm{Cu}(\mathrm{II})$ ions in solution. M2TM was solubilized in octyl- $\beta$-D-glucopyranoside $(\mathrm{OG})$ in $1 \mathrm{~mL}$ of $\mathrm{pH} 4.5$ water, then mixed with the $1 \mathrm{~mL}$ lipid vesicle solution to reach an OG concentration of 12 $\mathrm{mg} / \mathrm{mL}$. The solution was vortexed for 2 hours and dialyzed against $1 \mathrm{~L} \mathrm{pH} 4.5$ water at $4^{\circ} \mathrm{C}$ for 3 days with water changes every 12 hours to remove the detergent. The proteoliposome solution was centrifuged at $150,000 \mathrm{~g}$ and $\sim 4^{\circ} \mathrm{C}$ for 4 hours to give a membrane pellet with $\sim 45 \%$ hydration. The pellet was transferred into $4 \mathrm{~mm}$ MAS rotors for solid-state NMR experiments. The molar ratio of peptide to lipids (not including cholesterol) was 1: 15. A peptide-free POPC membrane was prepared without dialysis as a control for the PRE experiments. The tetrameric assembly and channel activity of the transmembrane M2 peptide in lipid bilayers have been confirmed by various biophysical experiments and functional assays $7,38,39$.

\section{$\mathrm{Cu}(\mathrm{II})$-containing membrane samples}

$\mathrm{Cu}$ (II) ions were incorporated into the membrane sample by direct titration of copper chloride solution into the MAS rotor. The M2TM monomer concentration in our samples at a hydration level of $\sim 45 \mathrm{wt} \%$ is about $0.1 \mathrm{M}$, thus requiring a minimum amount of $0.025 \mathrm{M}$ $\mathrm{Cu}$ (II) to occupy all tetrameric channels. $\mathrm{Cu}$ (II) also complexes strongly with hydroxide ions in water to form insoluble copper hydroxide, with a solubility product constant $\mathrm{K}_{s p} \equiv\left[\mathrm{Cu}^{2+}\right]$ $\cdot\left[\mathrm{OH}^{-}\right]^{2}$ of $4.8 \cdot 10^{-20} \mathrm{MP}^{2}$. To minimize hydroxide binding and maintain a free $\mathrm{Cu}(\mathrm{II})$ concentration of $0.025 \mathrm{M}$, a low bulk pH of 5.1 is necessary (Fig. S1). In addition, $\mathrm{Cu}$ (II) also binds to lipid phosphates. Our titration tests showed that a moderate excess of 4 equivalents of $\mathrm{Cu}$ (II) per M2TM tetramer at a monomer: lipid molar ratio of 1:15 saturate the lipid phosphate binding site while yielding sufficient channel binding, as indicated by 
the ${ }^{13} \mathrm{C}$ PRE. At this $\mathrm{Cu}(\mathrm{II})$ : tetramer: lipid molar ratio of $4: 1: 60$, the sample $\mathrm{pH}$ was controlled at 4.8 to avoid $\mathrm{Cu}$ (II) precipitation by hydroxide ions. An appropriate amount of $\mathrm{Cu}$ (II) chloride solution was titrated into the membrane to reach the desired $\mathrm{pH}$ and concentration. After titration, the sample was subject to freeze-thawing again, followed by incubation overnight at $37^{\circ} \mathrm{C}$ in the closed rotor to allow $\mathrm{Cu}$ (II) equilibration within the membrane. The low $\mathrm{pH}$ of the final sample was confirmed by the His $37{ }^{15} \mathrm{~N}$ spectra shown below.

\section{Solid-state NMR experiments}

Solid-state NMR experiments were carried out on a Bruker DSX-400 MHz (9.4 Tesla) spectrometer using $4 \mathrm{~mm}$ triple-resonance MAS probes. Typical radiofrequency pulse lengths were $3.5-5.0 \mu \mathrm{s}$ for ${ }^{13} \mathrm{C}, 6.0 \mu \mathrm{s}$ for ${ }^{15} \mathrm{~N}, 3.0-4.0 \mu \mathrm{s}$ for ${ }^{1} \mathrm{H}$ and $5.0 \mu \mathrm{s}$ for ${ }^{31} \mathrm{P} .{ }^{13} \mathrm{C},{ }^{15} \mathrm{~N}$, and ${ }^{31} \mathrm{P}$ chemical shifts were respectively referenced to the a-Gly ${ }^{13} \mathrm{CO}$ signal at $176.465 \mathrm{ppm}$ on the TMS scale, the ${ }^{15} \mathrm{~N}$ signal of $\mathrm{N}$-acetyl-valine at $122.0 \mathrm{ppm}$ on the liquid ammonia scale, and the hydroxyapatite signal at +2.73 on the phosphoric acid scale. Sample temperature was regulated using the built-in heater in the MAS probes and a Kinetics Thermal System XR air-jet sample cooler.

${ }^{13} \mathrm{C} \mathrm{T}_{1}$ relaxation times were measured using Torchia's z-filter sequence ${ }^{40}$ under $8 \mathrm{kHz}$ MAS. ${ }^{31} \mathrm{P}$ spectra were measured by direct polarization under 5-6 kHz MAS at $298 \mathrm{~K}$. 1D double-quantum (DQ) filtered ${ }^{13} \mathrm{C}$ spectra were measured to detect the ${ }^{13} \mathrm{C}$ signals of the labeled peptide without lipid background signals. The SPC5 recoupling sequence ${ }^{41}$ was used to excite and reconvert ${ }^{13} \mathrm{C}-{ }^{13} \mathrm{C}$ DQ coherence under $5-7 \mathrm{kHz}$ MAS. $2 \mathrm{D}{ }^{13} \mathrm{C}-{ }^{13} \mathrm{C}$ and ${ }^{15} \mathrm{~N}-{ }^{13} \mathrm{C}$ correlation spectra were measured at $243 \mathrm{~K}$ for resonance assignment of the peptide signals. $2 \mathrm{D}{ }^{13} \mathrm{C}-{ }^{13} \mathrm{C}$ correlation spectra were measured using a $40 \mathrm{~ms}$ spin diffusion mixing time under $6-9 \mathrm{kHz}$ MAS. $2 \mathrm{D}{ }^{15} \mathrm{~N}-{ }^{13} \mathrm{C}$ correlation spectra were measured under 7 $\mathrm{kHz}$ MAS using a REDOR-based pulse sequence ${ }^{42}$ with a mixing time of $0.8 \mathrm{~ms}$, which mainly gave one-bond ${ }^{15} \mathrm{~N}-{ }^{13} \mathrm{Ca}$ cross peaks.

\section{Results}

\section{Distance extraction using $\mathrm{Cu}(\mathrm{II}) \mathrm{PRE}$}

We first summarize quantitative aspects of distance extraction from $\mathrm{Cu}$ (II)-induced PRE. The longitudinal relaxation enhancement, $\Gamma_{1}$, is the difference between the relaxation rates in the absence and presence of the paramagnetic ion,

$$
\Gamma_{1}=\frac{1}{T_{1}^{p a r a}}-\frac{1}{T_{1}^{\text {dia }}}
$$

The transverse PRE, $\Gamma_{2}$, can be similarly defined. If we assume a diamagnetic ${ }^{13} \mathrm{C} T_{1}^{\text {dia }}$ of $1.0 \mathrm{~s}$, which is typical for the backbone carbons of membrane-bound proteins at moderate MAS frequencies, then we obtain the dependence of ${ }^{13} \mathrm{C} \Gamma_{1}$ on $T_{1}^{\text {para }}$ as shown in Fig. 1a. To obtain a $\Gamma_{1}$ larger than $10 \mathrm{~s}^{-1}$, which corresponds to a $\mathrm{Cu}(\mathrm{II})-{ }^{13} \mathrm{C}$ distance of less than $8 \AA$ (eq. 4), $T_{1}^{\text {para }}$ must be shorter than $0.1 \mathrm{~s}$.

The paramagnetic relaxation enhancement of nuclear spins under a metal-centered approximation for the unpaired electron depends on the electron-nucleus distances $r$ according to the Solomon-Bloembergen equations $9,12,43$. 


$$
\Gamma_{1}=\frac{2}{15}\left(\frac{\mu_{0}}{4 \pi}\right)^{2} \frac{\gamma_{n}^{2} g_{e}^{2} \mu_{B}^{2} S(S+1)}{r^{6}} \cdot\left(\frac{3 \tau_{c 1}}{1+\omega_{n}^{2} \tau_{c 1}^{2}}+\frac{7 \tau_{c 2}}{1+\omega_{e}^{2} \tau_{c 2}^{2}}\right)
$$

Here, $\mu_{0}=4 \pi \times 10^{-7} \mathrm{Tm} / \mathrm{A}$ is the vacuum permeability, $\gamma_{\mathrm{n}}$ is the nuclear-spin gyromagnetic ratio and equals $2 \pi \times 10.705 \mathrm{MHz} / \mathrm{T}$ for ${ }^{13} \mathrm{C}, g_{e}$ is the electron spin $g$-factor, $\mu_{B}=9.274 \times 10^{-24} \mathrm{~J} / \mathrm{T}$ is the Bohr magneton, $\mathrm{S}$ is the electron-spin quantum number of the paramagnetic ion, and $\omega_{n}$ and $\omega_{e}$ are the Larmor frequencies of the nucleus and electron at the magnetic field of interest. The longitudinal and transverse correlation times, $\tau_{\mathrm{c} 1}$ and $\tau_{\mathrm{c} 2}$, depend on the electronic relaxation time $\mathrm{T}_{1 \mathrm{e}}$ and $\mathrm{T}_{2 \mathrm{e}}$, the rotational correlation time $\left(\boldsymbol{\tau}_{\mathrm{r}}\right)$ of the molecule, and the exchange correlation time $\left(\tau_{\mathrm{M}}\right)$ :

$$
\frac{1}{\tau_{c 1}}=\frac{1}{T_{1 e}}+\frac{1}{\tau_{r}}+\frac{1}{\tau_{M}} \text { and } \frac{1}{\tau_{c 2}}=\frac{1}{T_{2 e}}+\frac{1}{\tau_{r}}+\frac{1}{\tau_{M}}
$$

To a good approximation, $\mathrm{T}_{1 \mathrm{e}}=\mathrm{T}_{2 \mathrm{e}}$. For solids without chemical exchange, $\tau_{\mathrm{r}}$ and $\tau_{\mathrm{M}}$ are long, thus $\tau_{\mathrm{c} 1}$ and $\tau_{\mathrm{c} 2}$ are approximately equal to the electronic relaxation times. The $\mathrm{T}_{1 \mathrm{e}}$ of $\mathrm{Cu}$ (II) has been estimated to be in the $1-5 \mathrm{~ns}$ range ${ }^{44}$. Since $\Gamma_{1}$ is roughly linear with $\mathrm{T}_{1 \mathrm{e}}$ but to the inverse sixth power of distance, it is much more sensitive to the distance than to $\mathrm{T}_{1 \mathrm{e}}$. Fig. $1 \mathrm{~b}$ shows the dependence of $r$ on $\mathrm{T}_{1 \mathrm{e}}$ for $\Gamma_{1}$ values of $0.35-200 \mathrm{~s}^{-1}$. For a given $\Gamma_{1}$, the distance is largely invariant with $\mathrm{T}_{1 \mathrm{e}}$ for $\mathrm{T}_{1 \mathrm{e}}>1 \mathrm{~ns}$. For example, for $\Gamma_{1}=4 \mathrm{~s}^{-1}$, a distance of $9.4 \pm 0.4 \AA$ is obtained for $T_{1 e}$ of $1-5 \mathrm{~ns}$. For $\Gamma_{1}=0.35 \mathrm{~s}^{-1}$, a longer distance of $15 \AA$ with a small uncertainty of $\pm 0.70 \AA$ is obtained. Therefore, we use an intermediate $\mathrm{T}_{1 \mathrm{e}}$ value of $2.5 \mathrm{~ns}$ in the following distance analysis.

Inputting the various constants and using a magnetic field of 9.4 Tesla, we obtain the distance-dependent ${ }^{13} \mathrm{C} \mathrm{T}_{1}$ PRE:

$$
\Gamma_{1}=\frac{3.648 \times 10^{-54} \mathrm{~Hz} \cdot \mathrm{m}^{6}}{r^{6}}
$$

Fig. 1c plots $r$ as a function of $\Gamma_{1}$, which allows us to estimate the limiting measurable ${ }^{13} \mathrm{C}$ $\mathrm{Cu}$ (II) distances. Assuming a minimum $T_{1}^{\text {para }}$ of $50 \mathrm{~ms}$ before the onset of severe line broadening, a $\Gamma_{1}$ of $\sim 20 \mathrm{~s}^{-1}$ is obtained, corresponding to a minimum ${ }^{13} \mathrm{C}-\mathrm{Cu}$ (II) distance of about $7.5 \AA$. At the other extreme, if the closest $T_{1}^{\text {para }}$ that can be resolved from a $T_{1}^{\text {dia }}$ of 1.0 $\mathrm{s}$ is $0.9 \mathrm{~s}$, then the $\Gamma_{1}$ of $0.11 \mathrm{~s}-1$ corresponds to a maximum ${ }^{13} \mathrm{C}-\mathrm{Cu}$ (II) distance of $18 \AA$. This is a conservative upper limit because at higher MAS frequencies, the ${ }^{13} \mathrm{C}_{1}$ will lengthen due to suppression of spin diffusion, which will allow smaller $\Gamma_{1}$ values to be resolved to detect longer distances. For distances shorter than 7.5 $\AA$, transverse PRE is expected to become dominant to broaden the spectra. Isotropic PCS may also become observable; however this effect is generally weak for $\mathrm{Cu}$ (II) due to its small $g$-tensor anisotropy and thus less useful for structure determination.

\section{$\mathrm{Cu}$ (II) binding to the lipid membrane}

Mutagenesis and electrophysiological experiments suggested the high-affinity $\mathrm{Cu}$ (II) binding site to be His 37, with a possible equilibrium reaction of $\mathrm{Cu}^{2+}+4 \mathrm{His} \ddot{\mathrm{A}}$ $\left[\mathrm{Cu}(\mathrm{His})_{4}\right]^{2+}$. However, in hydrated lipid membranes, two other $\mathrm{Cu}(\mathrm{II})$ binding equilibria are also present. $\mathrm{Cu}$ (II) can bind to lipid phosphate groups with 2: 1 or 1 : 1 stoichiometry 45,46 . No binding constant has been reported, but the dissociation constants for a number of other 
divalent cations such as $\mathrm{Mn}^{2+}$ and $\mathrm{Co}^{2+}$ were found to be in the $1-4 \mathrm{M}$ range ${ }^{45}$. $\mathrm{Cu}$ (II) also binds hydroxide ions in solution, but this binding is minimized by using acidic $\mathrm{pH}$ for our samples. Below we first assess the extent of $\mathrm{Cu}$ (II) binding to the membrane surface and its effects on the lipid signals. We measured the ${ }^{31} \mathrm{P}$ and ${ }^{13} \mathrm{C}$ spectra of protein-free POPC bilayers and the lipid ${ }^{13} \mathrm{C} \mathrm{T}_{1}$ in the absence and presence of $\mathrm{Cu}(\mathrm{II})$. A low $\mathrm{Cu}(\mathrm{II})$ : lipid mole ratio of 1: 15 , which was identical to the molar ratio of most protein-containing samples, was used. Fig. 2a shows that the ${ }^{31} \mathrm{P}$ MAS signal is completely suppressed after addition of $\mathrm{Cu}$ (II), confirming ion binding to the phosphate. In comparison, the headgroup $\mathrm{Ca}$ and glycerol G3 carbons, which are the closest carbons to the phosphate, retain the ${ }^{13} \mathrm{C}$ signals but exhibit line broadening and small frequency changes of $0.3-0.4 \mathrm{ppm}$. These frequency changes are not due to Fermi contact shift, since there is no covalent bonding or orbital overlap between the unpaired electron of $\mathrm{Cu}(\mathrm{II})$ and lipid carbons. They are also unlikely to be due to lipid conformational changes. First, even at higher ion concentrations than used here, multivalent metal ions only affect the polar headgroup $a$ and $\beta$ segments, as detected through ${ }^{2} \mathrm{H}$ quadrupolar couplings ${ }^{47,48}$. No ${ }^{2} \mathrm{H}$ quadrupolar coupling change was observed for glycerol backbone groups, in contrast to the G3 chemical shift change detected here. Second, our previous PRE studies using the divalent cation $\mathrm{Mn}(\mathrm{II})$, which has similar charge-charge interactions with the lipid phosphates as $\mathrm{Cu}(\mathrm{II})$, did not show any ${ }^{13} \mathrm{C}$ chemical shift changes ${ }^{20,22}$. Therefore, the $\mathrm{G} 3$ and $\mathrm{Ca}$ chemical shift changes in the $\mathrm{Cu}$ (II)bound membrane most likely result from pseudocontact shifts. Fig. 2b shows a representative pair of ${ }^{13} \mathrm{C} \mathrm{T}_{1}$ relaxation curves: the $\mathrm{T}_{1}$ of glycerol $\mathrm{G} 3$ decreased from 206 ms to $37 \mathrm{~ms}$ upon $\mathrm{Cu}(\mathrm{II})$ binding. Plotting the ${ }^{13} \mathrm{C} \Gamma_{1}$ for all lipid groups as a function of their depths from the membrane surface, we obtained the expected monotonic trend of decreasing $\Gamma_{1}$ with increasing distance from the membrane surface (Fig. $2 \mathrm{c}$ ). The $\Gamma_{1}$ values range from 22 to $0.3 \mathrm{~s}^{-1}$ (Table $\mathrm{S} 1$ ), corresponding to effective $\mathrm{Cu}$ (II) $-{ }^{13} \mathrm{C}$ distances of 7.4 $-15 \AA$. These values correlate well qualitatively with the depth of the lipid carbons to the membrane surface, which are known from diffraction data ${ }^{49}$. Quantitatively, the glycerol G3 and headgroup $\mathrm{Ca}$ carbons have longer PRE distances $(\sim 7.5 \AA)$ than their depths or distances to the phosphate. This discrepancy can be understood by the fact that $\mathrm{Cu}$ (II) ions laterally diffuse on the surface of the neutral lipid membrane ${ }^{45,46}$, with residence times at an individual lipid headgroup much shorter than $10^{-6} \mathrm{~s}{ }^{47,48}$, thus reducing the PRE effect through $\langle r\rangle^{-6}$ and a shorter correlation time ${ }^{50}$. For acyl-chain carbons, this distanceaveraging effect is attenuated because the significant depths of these carbons make the instantaneous distances to the surface $\mathrm{Cu}$ (II) ions more comparable. Overall, Table S1 shows that for the bottom half of the acyl chain carbons, the relaxation enhancement due to the surface-bound $\mathrm{Cu}$ (II) is $0.1-1 \mathrm{~s}^{-1}$. Therefore, if protein residues well embedded in the middle of the membrane experience ${ }^{13} \mathrm{C} \mathrm{T}_{1}$ PREs that are much larger than this range, then a $\mathrm{Cu}$ (II) binding site in the protein must exist at much closer proximity than the surface-bound $\mathrm{Cu}(\mathrm{II})$.

\section{$\mathrm{Cu}(\mathrm{II})$-induced ${ }^{13} \mathrm{C}$ PRE of membrane-bound M2TM}

To determine the specific binding site of $\mathrm{Cu}(\mathrm{II})$ in $\mathrm{M} 2$, we measured the ${ }^{13} \mathrm{C} \mathrm{T}_{1}$ PRE of nine transmembrane residues, including Val28, Ser31, Ile32, Gly34, Leu36, His37, Ile39, Leu40 and Trp41. Fig. 3a shows the aliphatic region of the ${ }^{13} \mathrm{C}$ spectra of Val28, Ser31, Ile32, Leu36-labeled M2TM in the absence and presence of $\mathrm{Cu}(\mathrm{II})$. Among the four labeled residues, Leu36 $\mathrm{Ca}$ and $\mathrm{C} \beta$ exhibited the strongest line broadening, as shown in both 1D and $2 \mathrm{D}{ }^{13} \mathrm{C}$ spectra (Fig. S2), indicating that Leu36 is the closest to $\mathrm{Cu}$ (II) among the four labeled residues. Fig. $3 \mathrm{~b}-\mathrm{e}$ shows the ${ }^{13} \mathrm{C} \mathrm{T}_{1}$ relaxation curves of $\mathrm{Cu}$ (II)-free and $\mathrm{Cu}(\mathrm{II})$ bound samples. In addition to the 4:1 Cu(II): tetramer sample, we also examined the spectra of a 1:1 Cu(II): tetramer sample to observe the progression of PRE effects. Sizeable $\mathrm{T}_{1}$ relaxation enhancement was detected for all residues. At the $4: 1$ ratio, ${ }^{13} \mathrm{C} \Gamma_{1}$ ranges from 1.5 to $2.6 \mathrm{~s}^{-1}$ (Table 1), which corresponds to distances of $11.6-10.6 \AA$ to the $\mathrm{Cu}$ (II) center. 
In addition to enhancing ${ }^{13} \mathrm{C}$ longitudinal and transverse relaxation, $\mathrm{Cu}$ (II) binding also perturbed the ${ }^{15} \mathrm{~N}$ chemical shift of Ser31 from $117.9 \mathrm{ppm}$ in the apo state to $114.1 \mathrm{ppm}$ in the $\mathrm{Cu}$ (II) bound state (Fig. 3f). This large shift cannot be due to PCS but must result from $\mathrm{Cu}$ (II)-induced conformational change of this residue. We previously showed that Ser31 is the site of maximal chemical shift perturbation by amantadine, where the ${ }^{15} \mathrm{~N}$ chemical shift increased from $115 \mathrm{ppm}$ in the apo state to $121 \mathrm{ppm}$ in the drug-bound state in DLPC bilayers ${ }^{51}$. Similar ${ }^{15} \mathrm{~N}$ chemical shift increase was also observed when M2TM was bound to virus-mimetic membranes ${ }^{34}$. The fact that $\mathrm{Cu}$ (II) binding changed the $\mathrm{Ser} 31{ }^{15} \mathrm{~N}$ chemical shift in the opposite direction indicates that $\mathrm{Cu}(\mathrm{II})$ affects M2TM conformation differently from amantadine.

Fig. 4 shows the ${ }^{13} \mathrm{C}$ and ${ }^{15} \mathrm{~N}$ spectra of GHI-M2TM in the absence and presence of $\mathrm{Cu}(\mathrm{II})$. The ${ }^{13} \mathrm{C}$ spectra were measured with a ${ }^{13} \mathrm{C}$ double-quantum filter to suppress the lipid natural abundance ${ }^{13} \mathrm{C}$ signals. Among the three residues, the His 37 signals were nearly completely quenched by $\mathrm{Cu}$ (II) $(<18 \%$ residual intensity), while Ile39 retained the most intensities. The aromatic signals of His 37 were largely undetectable, as shown by both 1D and $2 \mathrm{D}{ }^{13} \mathrm{C}$ correlation spectra (Fig. $4 \mathrm{~b}$, c). These results strongly indicate that $\mathrm{Cu}$ (II) binds to His37. For the detectable Gly34 and Ile39 residues, most sites exhibited clear $\mathrm{T}_{1}$ relaxation enhancement (Fig. S3a, b). In addition, the resolved lipid ${ }^{13} \mathrm{C}$ signals such as glycerol backbone G2 showed comparable $\mathrm{T}_{1}$ PRE as the protein-free membrane (Fig. S3c), indicating that $\mathrm{Cu}(\mathrm{II})$ binds to the membrane surface similarly whether the protein is present or not. In addition to causing PRE, $\mathrm{Cu}$ (II) also perturbed the conformation of Gly34: the apo peptide exhibited two Gly34 CO peaks at 175.6 and $173.2 \mathrm{ppm}$ while the $\mathrm{Cu}(\mathrm{II})$-bound peptide showed a CO peak at $172.2 \mathrm{ppm}$. Previous chemical shift analysis ${ }^{52}$ and orientation measurements ${ }^{53}$ indicated that the downfield CO peak at $175 \mathrm{ppm}$ corresponded to M2TM with a kink at Gly34, while a straight TM helix exhibited the more upfield Gly34 CO chemical shift.

In principle, $\mathrm{Cu}(\mathrm{II})$ can bind to either $\mathrm{N} \varepsilon 2$ or $\mathrm{N} \delta 1$ of His37, which faces the C-terminus and $\mathrm{N}$-terminus of the channel, respectively, due to the trans-trans rotamer of the His 37 sidechain ${ }^{54,55}$. To determine which nitrogen coordinates $\mathrm{Cu}(\mathrm{II})$, we measured the ${ }^{15} \mathrm{~N}$ MAS spectra of His37-labeled M2TM. Previous $2 \mathrm{D}{ }^{15} \mathrm{~N}-{ }^{13} \mathrm{C}$ correlation spectra showed that the two nitrogens of the imidazolium ring differed in their isotropic chemical shifts by $4.1 \mathrm{ppm}$ : $\mathrm{N} \varepsilon 2$ resonates at $176.3 \mathrm{ppm}$ while $\mathrm{N} \delta 1$ resonates at $180.4 \mathrm{ppm}^{54}$, due to the higher proton affinity of $\mathrm{Ne} 2$ throughout a large $\mathrm{pH}$ range. Fig. $4 \mathrm{~d}$ shows that $\mathrm{Cu}$ (II) binding completely suppressed the upfield $\mathrm{N} \varepsilon 2$ peak while retaining $~ 10 \%$ of the $\mathrm{N} \delta 1$ signal, suggesting that $\mathrm{Cu}$ (II) binds preferentially to $\mathrm{N} \varepsilon 2$.

If $\mathrm{N} \varepsilon 2$ binding is correct, then residues immediately C-terminal to His 37 should manifest larger PRE than residues immediately N-terminal to His37. To test this hypothesis, we measured the ${ }^{13} \mathrm{C}$ PRE of LW-M2TM. Indeed, both the backbone and sidechain ${ }^{13} \mathrm{C}$ signals of Leu40 and Trp41 exhibited significant line broadening (Fig. 5a), with Ca peaks decreasing to $20-30 \%$ of the apo intensities. ${ }^{13} \mathrm{C} \mathrm{T}_{1}$ relaxation rates also increased substantially. Leu $40 \mathrm{Ca}$ gave a $\Gamma_{1}$ of $8.67 \mathrm{~s}^{-1}$, corresponding to a distance of $\sim 8.7 \AA$ to $\mathrm{Cu}$ (II) (Table 1). This $\Gamma_{1}$ was much larger than the Gly34 Ca $\Gamma_{1}$ of $3.46 \mathrm{~s}^{-1}$. Since Leu40 and Gly34 are both three residues away from His37, their different PRE lends further support to the conclusion that $\mathrm{Cu}$ (II) binds the imidazolium rings from the $\mathrm{C}$-terminal side, between His37 and Trp41.

Table 1 lists the ${ }^{13} \mathrm{C} \mathrm{T}_{1}$ PREs and the resulting distances for all labeled residues. The ${ }^{13} \mathrm{C}$ intensity reduction, measured as the ratio $P^{\text {para }} / I^{\text {dia }}$ between the $\mathrm{Cu}$ (II) bound sample and the diamagnetic sample, is also listed to reflect the qualitative $T_{2}$ relaxation enhancement. For the intensity-suppressed His37, a conservative distance upper limit of $7.5 \AA$ was used, 
although the actual distances of $\mathrm{Cu}$ (II) to the imidazolium sidechain atoms are almost certainly much shorter. The central segment of the TM helix, from Gly34 to Leu40, manifests longitudinal PRE in the range of 3-9 $\mathrm{s}^{-1}$ (Table 1), which is an order of magnitude larger than the PRE of lipid chain carbons at comparable depths from the membrane surface (Table S1). This confirms the presence of a high-affinity $\mathrm{Cu}$ (II) binding site within this segment, which is chiefly responsible for the PRE effects of these residues. Fig. 6a plots the residual $\mathrm{Ca}$ intensities after $\mathrm{Cu}$ (II) binding. The minimum intensity occurs at His37, indicating the $\mathrm{Cu}(\mathrm{II})$ binding site. Gly34 $\mathrm{Ca}$ also showed low intensity. However, this value does not accurately reflect a very short distance to the $\mathrm{Cu}$ (II) center, because the $\mathrm{CH}_{2} \mathrm{Ca}$ group of Gly experiences more severe ${ }^{1} \mathrm{H}$ signal quenching by $\mathrm{Cu}$ (II) than the $\mathrm{CH}$ $\mathrm{Ca}$ group of other amino acids, thus disproportionally reducing the $\mathrm{Ca}$ intensity through ${ }^{1} \mathrm{H}_{-}{ }^{13} \mathrm{C}$ cross polarization. Fig. $6 \mathrm{~b}$ compares the ${ }^{13} \mathrm{C} \mathrm{T}_{1}$ PRE of $\mathrm{Ca}$ sites with their intensity reduction factors. The non-Gly residues show a significant correlation between $\Gamma_{1}$ and intensity reduction, consistent with the common $r^{-6}$ dependence of $\Gamma_{1}$ and $\Gamma_{2}$. Although the His $37 \mathrm{Ca} \Gamma_{1}$ could not be measured, based on its intensity reduction factor, a $\Gamma_{1}$ of about $10 \mathrm{~s}^{-1}$ is expected.

Fig. 7 shows the structural model of $\mathrm{Cu}(\mathrm{II})$ binding to His 37 in M2TM. We used the $1.65 \AA$ crystal structure (PDB: $3 \mathrm{LBW}$ ) to model $\mathrm{Cu}(\mathrm{II})$ distances to various residues, but the same conclusion was reached when using the recent solid-state NMR structure (PDB: 2KQT) of $\mathrm{M}^{2} \mathrm{TM}^{56}$. We placed $\mathrm{Cu}$ (II) at the center of the square formed by the four equivalent His37 $\mathrm{N \varepsilon} 2$ atoms. Thus positioned, the $\mathrm{Cu}$ (II) ion is $\sim 3.0 \AA$ from the nitrogens at the four corners, which is within the literature range of $\mathrm{Cu}(\mathrm{II})$ distances to histidine nitrogens ${ }^{57}$. This $\mathrm{Ne2}$ binding site yields distances in good agreement with the PRE-measured values for the central segment of the TM helix (Table S2). Compared to the alternative N $\delta 1$ binding model, the $\mathrm{Ne} 2$ binding model has longer distances to the $\mathrm{N}$-terminal residues and shorter ones to the $\mathrm{C}$-terminal residues. The largest distance difference between the two models occurs at Gly34 $\mathrm{Ca}$, which is $8.7 \AA$ from the $\mathrm{N} \varepsilon 2$-bound $\mathrm{Cu}$ (II) but only $6.3 \AA$ from the $\mathrm{N} \delta 1$ binding site. The latter would correspond to a $\Gamma_{1}$ of about $60 \mathrm{~s}^{-1}$, which is not detected. Moreover, such a short distance would imply complete quenching of the Gly34 signals, which is inconsistent with the experimental data (Fig. 4a). Another key difference between the two binding sites is the relative distance between Leu36 and Leu40. Cu(II) binding at the upper N $\delta 1$ site would predict a shorter distance to Leu36 than to Leu40, which is opposite the trend seen in the spectral intensities (less residual intensities for Leu40) and the $\mathrm{T}_{1}$ PRE (higher $\Gamma_{1}$ for Leu40). Taken together, the quantitative ${ }^{13} \mathrm{C} \Gamma_{1}$ and the spectral line broadening consistently support His $37 \mathrm{~N} \varepsilon 2$ as the $\mathrm{Cu}(\mathrm{II})$ binding site.

For residues close to the termini of the TM peptide, the measured PRE distances are shorter than the predicted distances to the His $37 \mathrm{Ne} 2$ binding site. The discrepancy is especially

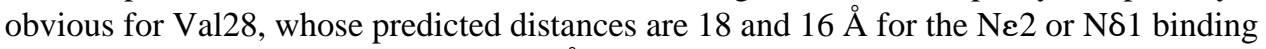
sites, while the measured distance is $11 \AA$ (Table S2). This discrepancy results from the fact that Val28 is much closer to the membrane surface (10-11 $⿱$ ) than to His37 (Table S2), thus should experience significant PRE effects from the surface-bound $\mathrm{Cu}(\mathrm{II})$.

\section{Discussion}

\section{High affinity binding site of $\mathrm{Cu}(\mathrm{II})$ at His37 Nع2: a His-Trp "cage" binding model}

The observed ${ }^{13} \mathrm{C}$ and ${ }^{15} \mathrm{~N}$ spectral broadening ( $\mathrm{T}_{2}$ PRE) and ${ }^{13} \mathrm{C} \mathrm{T}_{1}$ PRE indicate that $\mathrm{Cu}$ (II) binds to His37 Ne2, not far from the gating residue Trp41 (Fig. 7). Metal chelation to imidazole $\mathrm{N} \varepsilon 2$ in favor of $\mathrm{N} \delta 1$ has been often observed in proteins $18,57,58$. In the case of $\mathrm{M} 2, \mathrm{Cu}(\mathrm{II})$ entrapment in the aromatic cage formed by the four imidazolium rings and four indole rings enhances the $\mathrm{Cu}$ (II) affinity compared to binding to $\mathrm{N} \delta 1$ on the $\mathrm{N}$-terminal side, where $\mathrm{Cu}(\mathrm{II})$ can dissociate more readily. By binding between the His37 and Trp41 tetrads, 
$\mathrm{Cu}$ (II) can inhibit the proton current in multiple ways, including perturbing His37-water proton exchange ${ }^{59}$, preventing His37 conformational dynamics ${ }^{54}$, and interfering with HisTrp cation- $\pi$ interaction ${ }^{60,61}$. The $\mathrm{N} \varepsilon 2$ coordination of $\mathrm{Cu}(\mathrm{II})$ implicitly disagrees with a structural model where $\mathrm{N} \varepsilon 2$ of a charged imidazolium hydrogen-bonds with $\mathrm{N} \delta 1$ of a neutral imidazole ${ }^{62}$. At the low $\mathrm{pH}$ used for the NMR samples, both $\mathrm{N} \varepsilon 2$ and $\mathrm{N} \delta 1$ are initially protonated, thus $\mathrm{Cu}$ (II) binding to $\mathrm{N} \varepsilon 2$ must at first displace a proton, which is consistent with the slower onset of $\mathrm{Cu}(\mathrm{II})$ inhibition at low $\mathrm{pH}$ than at high $\mathrm{pH}$.

When $\mathrm{Cu}$ (II) solution was injected into internally high-pH oocytes that are bathed in externally low $\mathrm{pH}$ solution, it did not inhibit wild-type M2 channels but inhibited the W41A mutant channel. This was interpreted as the inability of $\mathrm{Cu}(\mathrm{II})$ to pass the bulky Trp indole rings from the $\mathrm{C}$-terminal side, an effect that was removed by mutation to the smaller Ala. At the symmetric low $\mathrm{pH}$ condition used in our SSNMR samples, $\mathrm{Cu}$ (II) entry to the His37 binding site is more likely bidirectional, since the Trp41 gate should be open at acidic pH, as indicated by NMR distance measurements ${ }^{8}$ and crystal structures ${ }^{55,63}$. In principle, it would be interesting to measure $\mathrm{Cu}$ (II) binding at higher $\mathrm{pH}$ where the Trp41 gate is closed and the $\mathrm{Cu}$ (II) affinity for His37 is higher. However, to avoid $\mathrm{Cu}$ (II) binding to the more abundant hydroxide ions present at higher $\mathrm{pH}$, a much lower concentration of $\mathrm{Cu}$ (II) must be used, which would in turn require a much lower concentration of protein than feasible by solid-state NMR in the absence of sensitivity-enhancement techniques.

\section{Low affinity binding site for $\mathrm{Cu}(\mathrm{II})$}

The current ${ }^{13} \mathrm{C}$ PRE data strongly suggest that the low affinity $\mathrm{Cu}(\mathrm{II})$ binding site seen in the electrophysiological data ${ }^{33}$ is the lipid phosphate on the membrane surface. Even at a low $\mathrm{Cu}$ (II) concentration, the surface-bound $\mathrm{Cu}$ (II) caused detectable PRE to Val28, which is relatively far from His 37 but closer to the membrane surface. Inspection of the ${ }^{31} \mathrm{P}$ spectra of the lipids and $2 \mathrm{D}{ }^{15} \mathrm{~N}-{ }^{13} \mathrm{C}$ spectra of VSIL-M2TM (Fig. S4) upon Cu(II) titration from 0 , 1: 1 to $4: 1 \mathrm{Cu}$ (II): tetramer ratios gave useful insight into the $\mathrm{Cu}$ (II) binding process. The ${ }^{31} \mathrm{P}$ spectra showed a small residual intensity at the $1: 1$ ratio but no intensity at the $4: 1$ ratio. The Val28 peak became broadened already at the 1:1 ratio and broadened further at the 4:1 ratio. In comparison, the Ser31 peak did not shift from the apo position at the 1:1 ratio but moved significantly in the ${ }^{15} \mathrm{~N}$ dimension at the $4: 1$ ratio. These results indicate that the first $\mathrm{Cu}(\mathrm{II})$ ions bind to the membrane surface, causing weak PREs to the most surface-proximal residues. When the $\mathrm{Cu}$ (II) concentration increases, the membrane surface binding sites become saturated, fully suppressing the ${ }^{31} \mathrm{P}$ intensity. Additional $\mathrm{Cu}(\mathrm{II})$ ions then enter the channels to bind His37, and in so doing cause significant conformational changes at Ser31 and Gly34. Because of the immediate accessibility of the membrane surface to water and the necessity for ion diffusion into the channel pore to reach the His37 binding site, $\mathrm{Cu}$ (II) binding to the membrane surface is faster than to His37, which explains the fast initial kinetics seen in the proton conductivity measurements. However, the channel binding site with the slower kinetics has higher affinity, due to $\mathrm{Cu}$ (II) chelation with the imidazolium $\mathrm{N} \varepsilon 2$ as well as entrapment by the His-Trp cage.

The lipid phosphate binding model is consistent with biochemical evidence that the lowaffinity site is non-specific, has fast kinetics, and does not depend on various sidechains in the protein that could bind metal ions, including Cys17, Cys19, Asp24 and Ser31 33 . Membrane-surface bound $\mathrm{Cu}$ (II) may hinder proton conduction by influencing the conformation of the cytoplasmic domain of the full-length protein, which may in turn subtly perturb the conformation and packing of the TM helix. 


\section{$\mathrm{Cu}$ (II) versus amantadine-induced conformational changes of M2TM}

Electrophysiological data indicate both similarities and differences between $\mathrm{Cu}(\mathrm{II})$ inhibition and amantadine inhibition of the M2 proton channel. While both compounds inhibit the channel bidirectionally and better at high $\mathrm{pH}$, the $\mathrm{Cu}$ (II) binding affinity is about 10 -fold weaker than amantadine ${ }^{33} . \mathrm{Cu}$ (II) binding is also competitive with hydrophobic drugs: prior application of BL-1743 to M2 prevented Cu(II) inhibition. Since BL-1743 is believed to act similarly as amantadine, we can understand this competitive inhibition by the fact that amantadine and BL-1743 binding to the N-terminal pore ${ }^{56,63}$, at Ser31, occludes the channel, thus preventing $\mathrm{Cu}$ (II) entry to His37. An additional effect may be that amantadineinduced dehydration of the channel ${ }^{64}$ and the resulting perturbation of the His 37 protonation equilibria 53,59 may interfere with $\mathrm{Cu}(\mathrm{II})$ binding.

Consistent with the functional data, the observed ${ }^{13} \mathrm{C}$ and ${ }^{15} \mathrm{~N}$ chemical shifts indicate several differences between the $\mathrm{Cu}(\mathrm{II})$-bound and amantadine-bound M2TM conformations. Ser31 and Gly34 exhibit $\mathrm{Cu}(\mathrm{II})$-bound chemical shifts that are distinct from the amantadinebound chemical shifts 51,65 . The $\mathrm{Cu}$ (II)-bound chemical shifts at these sites are more consistent with a straighter TM helix at low $\mathrm{pH}^{52}$. These differences are clearly related to the distinct binding sites at His37 and Ser31. Therefore, the structural and mechanistic information obtained here suggests that it should be possible to design new drugs 66 to target the His 37 binding site as a route to inhibit the naturally occurring amantadine-resistant M2 mutants such as S31N and V27A.

\section{$\mathrm{Cu}(\mathrm{II})$ PRE for studying membrane proteins}

The distances extracted from ${ }^{13} \mathrm{C} \mathrm{T}_{1}$ PRE (Table 1 ) have relatively small uncertainties of $0.1-0.3 \AA$, as propagated from the random uncertainties in the measured $\mathrm{T}_{1}$ values. However, it is useful to evaluate the extent of systematic uncertainties, such as dynamics of the protein, uncertainty in the occupancy of the His 37 binding site, the presence of ${ }^{13} \mathrm{C}$ spin diffusion, and the effects of multiple $\mathrm{Cu}$ (II) ions on the ${ }^{13} \mathrm{C} \mathrm{PRE}$. In general, protein anisotropic motion and incomplete $\mathrm{Cu}$ (II) occupancy at its binding site will attenuate the PRE, whereas multi-spin effects due to multiple $\mathrm{Cu}$ (II) ions should increase the PRE. Thus, these error sources should partially cancel. More careful considerations indicate that each of these potential sources of uncertainties is in fact minimal under the conditions of our experiments. Due to the use of the cholesterol- and SM-rich VM+ membrane for M2TM reconstitution, no large-amplitude motion of the tetramer backbone is present ${ }^{35}$, in contrast to the situation in DMPC and POPC membranes ${ }^{67}$. The occupancy of the His 37 binding site is close to $100 \%$, otherwise significant residual imidazole intensities would be detected. While ${ }^{13} \mathrm{C}$ spin diffusion is present at the MAS frequency of $8 \mathrm{kHz}$ for the $\mathrm{T}_{1}$ experiments, the use of site-specifically labeled samples should present significant barrier to inter-residue spin diffusion, thus making ${ }^{13} \mathrm{C} \mathrm{T}_{1}$ values relatively site-specific, as verified by the measured values (Table 1). Finally, at the $\mathrm{Cu}(\mathrm{II})$ : tetramer: lipid molar ratio of 4: 1: 60 , the surface density of $\mathrm{Cu}$ (II) is low, with about $3 \mathrm{Cu}$ (II) per 60 lipids. With a typical lipid headgroup area of $60 \AA^{2}$, the average distance between two $\mathrm{Cu}$ (II) ions on the membrane surface is about $35 \AA$. This distance is much larger than the thickness of one leaflet of the bilayer, thus membrane-embedded residues should experience at most only one surfacebound $\mathrm{Cu}$ (II) in addition to the His37-bound $\mathrm{Cu}$ (II). The surface-bound $\mathrm{Cu}(\mathrm{II})$ is also dynamic with respect to the protein, which further weakens its PRE effect. Finally, the PRE of surface-bound $\mathrm{Cu}$ (II) can in principle be internally calibrated using the lipid ${ }^{13} \mathrm{C}$ signals if the approximate depths of the residues are known (Table S2). Therefore the surface $\mathrm{Cu}(\mathrm{II})$ PRE effects can be taken into account more quantitatively, if necessary, to analyze the PRE due to the protein-bound $\mathrm{Cu}(\mathrm{II})$. 
This study demonstrates that functionally important paramagnetic ions in membrane proteins can be used as a structural probe to both determine the metal binding site and provide long distance constraints. For M2, $\mathrm{Cu}$ (II) binding to histidine is sufficiently tight due to the binding site geometry that no dissociation is detected, and additional binding equilibria to hydroxide ions and lipid phosphates can be minimized or controlled using appropriate $\mathrm{pH}$ and $\mathrm{Cu}$ (II) concentration. For such functional binding sites in proteins, metal chelating agents cannot be used, thus alternative paramagnetic NMR approaches where metal chelates are covalently attached to protein sidechains ${ }^{10}$ or incorporated into lipids or solution ${ }^{68}$ are not applicable. This study shows that membrane proteins containing highaffinity paramagnetic metal ions should be generally amenable to structural investigation.

\section{Supplementary Material}

Refer to Web version on PubMed Central for supplementary material.

\section{Acknowledgments}

The authors would like to thank Professors Yoshitaka Ishii, Klaus Schmidt-Rohr and Claudio Luchinat for insightful discussions. This work is supported by NIH grant GM088204 to M. H.

\section{References}

1. Hong M. Acc Chem Res. 2006; 39:176-183. [PubMed: 16548506]

2. Hong M, Zhang Y, Hu F. Annu Rev Phys Chem. 2012; 63:1-24. [PubMed: 22136620]

3. Luca S, Heise H, Baldus M. Acc Chem Res. 2003; 36:858-65. [PubMed: 14622033]

4. Loquet A, Giller K, Becker S, Lange A. J Am Chem Soc. 2010; 132:15164-15166. [PubMed: 20932028]

5. De Paëpe G, Lewandowski JR, Loquet A, Böckmann A, Griffin RG. J Chem Phys. 2008; 129:245101. [PubMed: 19123534]

6. Schmidt-Rohr K, Hong M. J Am Chem Soc. 2003; 125:5648-5649. [PubMed: 12733900]

7. Luo W, Hong M. J Am Chem Soc. 2006; 128:7242-7251. [PubMed: 16734478]

8. Luo W, Mani R, Hong M. J Phys Chem. 2007; 111:10825-10832.

9. Solomon I. Phys Rev. 1955; 99:559-565.

10. Nadaud PS, Helmus JJ, Kall SL, Jaroniec CP. J Am Chem Soc. 2009; 131:8108-8120. [PubMed: 19445506]

11. Nayeem A, Yesinowski JP. J Chem Phys. 1988; 89:4600-4608.

12. Bertini I, Turano P, Vila AJ. Chem Rev. 1993; 93:2833-2932.

13. Lee H, Polenova T, Beer RH, McDermott AE. J Am Chem Soc. 1999; 121:6884-6894.

14. Wickramasinghe NP, Shaibat MA, Ishii Y. J Phys Chem B. 2007; 111:9693-9696. [PubMed: 17661508]

15. Balayssac S, Bertini I, Bhaumik A, Lelli M, Luchinat C. Proc Natl Acad Sci U S A. 2008; 105:17284-17289. [PubMed: 18988744]

16. Pintacuda G, Giraud N, Pierattelli R, Böckmann A, Bertini I, Emsley L. Angew Chem Int Ed Engl. 2007; 46:1079-1082. [PubMed: 17191298]

17. Nadaud PS, Helmus JJ, Höfer N, Jaroniec CP. J Am Chem Soc. 2007; 129:7502-7503. [PubMed: 17530852]

18. Parthasarathy S, Long F, Miller Y, Xiao Y, McElheny D, Thurber K, Ma B, Nussinov R, Ishii Y. J Am Chem Soc. 2011; 133:3390-3400. [PubMed: 21341665]

19. Aime S, Botta M, Mainero V, Terreno E. Magn Reson Med. 2002; 47:10-13. [PubMed: 11754437]

20. Buffy JJ, Hong T, Yamaguchi S, Waring A, Lehrer RI, Hong M. Biophys J. 2003; 85:2363-2373. [PubMed: 14507700]

21. Grobner G, Glaubitz C, Watts A. J Magn Reson. 1999; 141:335-9. [PubMed: 10579957] 
22. Su Y, Mani R, Hong M. J Am Chem Soc. 2008; 130:8856-8864. [PubMed: 18597439]

23. Tang M, Berthold DA, Rienstra CM. J Phys Chem Lett. 2011; 2:1836-1841. [PubMed: 21841965]

24. Yamamoto K, Xu J, Kawulka KE, Vederas JC, Ramamoorthy A. J Am Chem Soc. 2010; 132:6929-6931. [PubMed: 20433169]

25. Cady SD, Luo WB, Hu F, Hong M. Biochemistry. 2009; 48:7356-7364. [PubMed: 19601584]

26. Lamb, RA.; Holsinger, KJ.; Pinto, LH. Cellular Receptors of Animal Viruses. Wemmer, E., editor. Cold Spring Harbor Lab Press; Plainview, NY: 1994. p. 303-321.

27. Pinto LH, Lamb RA. J Biol Chem. 2006; 281:8997-9000. [PubMed: 16407184]

28. Wang J, Qiu JX, Soto CS, DeGrado WF. Curr Opin Struct Biol. 2011; 21:68-80. [PubMed: 21247754]

29. Wang C, Lamb RA, Pinto LH. Biophys J. 1995; 69:1363-1371. [PubMed: 8534806]

30. Tang Y, Zaitseva F, Lamb RA, Pinto LH. J Biol Chem. 2002; 277:39880-39886. [PubMed: 12183461]

31. Wang C, Takeuchi K, Pinto LH, Lamb RA. J Virol. 1993; 67:5585-5594. [PubMed: 7688826]

32. Balannik V, Wang J, Ohigashi Y, Jing X, Magavern E, Lamb RA, DeGrado WF, Pinto LH. Biochemistry. 2009; 48:11872-11882. [PubMed: 19905033]

33. Gandhi CS, Shuck K, Lear JD, Dieckmann GR, DeGrado WF, Lamb RA, Pinto LH. J Biol Chem. 1999; 274:5474-5482. [PubMed: 10026160]

34. Cady SD, Wang T, Hong M. J Am Chem Soc. 2011; 133:11572-11579. [PubMed: 21661724]

35. Luo W, Cady SD, Hong M. Biochemistry. 2009; 48:6361-6368. [PubMed: 19489611]

36. Masi D, Mealli CMS, Sabatini A, Vacca A, Zanobini F. Helv Chim Acta. 1984; 67:1818-1826.

37. Hegetschweiler K, Saltman P. Inorg Chem. 1986; 25:107-109.

38. Howard KP, Lear JD, DeGrado WF. Proc Natl Acad Sci USA. 2002; 99:8568-72. [PubMed: 12084917]

39. Ma C, Polishchuk AL, Ohigashi Y, Stouffer AL, Schön A, Magavern E, Jing X, Lear JD, Freire E, Lamb RA, DeGrado WF, Pinto LH. Proc Natl Acad Sci USA. 2009; 106:12283-12288. [PubMed: 19590009]

40. Torchia DA, Szabo A. J Magn Reson. 1982; 49:107-121.

41. Hohwy M, Rienstra CM, Jaroniec CP, Griffin RG. J Chem Phys. 1999; 110:7983-7992.

42. Hong M, Griffin RG. J Am Chem Soc. 1998; 120:7113-7114.

43. Bloembergen N. J Chem Phys. 1957; 27:572-573.

44. Bertini, I.; Luchinat, C.; Parigi, G. Solution NMR of paramagnetic molecules: applications to metallobiomolecules and models. Amsterdam; New York: Elsevier; 2001.

45. McLaughlin A, Grathwohl C, McLaughlin S. Biochim Biophys Acta. 1978; 513:338-357. [PubMed: 718897]

46. Puskin JS. J Membr Biol. 1977; 35:39-55. [PubMed: 196084]

47. Altenbach C, Seelig J. Biochemistry. 1984; 23:3913-3920. [PubMed: 6487586]

48. Seelig J, Macdonald PM, Scherer PG. Biochemistry. 1987; 26:7535-7541. [PubMed: 3322401]

49. Wiener MC, White SH. Biophys J. 1992; 61:434-447. [PubMed: 1547331]

50. DeMarco ML, Woods RJ, Prestegard JH, Tian F. J Am Chem Soc. 2010; 132:1334-1338. [PubMed: 20058858]

51. Cady SD, Mishanina TV, Hong M. J Mol Biol. 2009; 385:1127-1141. [PubMed: 19061899]

52. Hu F, Luo W, Cady SD, Hong M. Biochim Biophys Acta. 2011; 1808:415-423. [PubMed: 20883664]

53. Hu J, Asbury T, Achuthan S, Li C, Bertram R, Quine JR, Fu R, Cross TA. Biophys J. 2007; 92:4335-4343. [PubMed: 17384070]

54. Hu F, Luo W, Hong M. Science. 2010; 330:505-508. [PubMed: 20966251]

55. Acharya A, Carnevale V, Fiorin G, Levine BG, Polishchuk A, Balannick V, Samish I, Lamb RA, Pinto LH, DeGrado WF, Klein ML. Proc Natl Acad Sci U S A. 2010; 107:15075-15080.

[PubMed: 20689043] 
56. Cady SD, Schmidt-Rohr K, Wang J, Soto CS, DeGrado WF, Hong M. Nature. 2010; 463:689-692. [PubMed: 20130653]

57. Brinen LS, Willett WS, Craik CS, Fletterick RJ. Biochemistry. 1996; 35:5999-6009. [PubMed: 8634241]

58. Klabunde T, Eicken C, Sacchettini JC, Krebs B. Nat Struct Biol. 1998; 5:1084-1090. [PubMed: 9846879]

59. Hu F, Schmidt-Rohr K, Hong M. J Am Chem Soc. 2012; 134:3703-3713. [PubMed: 21974716]

60. Okada A, Miura T, Takeuchi H. Biochemistry. 2001; 40:6053-6060. [PubMed: 11352741]

61. Nishimura K, Kim S, Zhang L, Cross TA. Biochemistry. 2002; 41:13170-13177. [PubMed: 12403618]

62. Sharma M, Yi M, Dong H, Qin H, Peterson E, Busath D, Zhou HX, Cross TA. Science. 2010; 330:509-512. [PubMed: 20966252]

63. Stouffer AL, Acharya R, Salom D, Levine AS, Di Costanzo L, Soto CS, Tereshko V, Nanda V, Stayrook S, DeGrado WF. Nature. 2008; 451:596-599. [PubMed: 18235504]

64. Luo W, Hong M. J Am Chem Soc. 2010; 132:2378-2384. [PubMed: 20112896]

65. Cady SD, Hong M. Proc Natl Acad Sci USA. 2008; 105:1483-1488. [PubMed: 18230730]

66. Wang J, Ma C, Fiorin G, Carnevale V, Wang T, Hu F, Lamb RA, Pinto LH, Hong M, Klein ML, DeGrado WF. J Am Chem Soc. 2011; 133:12834-12841. [PubMed: 21744829]

67. Cady SD, Goodman C, Tatko C, DeGrado WF, Hong M. J Am Chem Soc. 2007; 129:5719-5729. [PubMed: 17417850]

68. Linser R, Fink U, Reif B. J Am Chem Soc. 2009; 131:13703-13708. [PubMed: 19736939] 

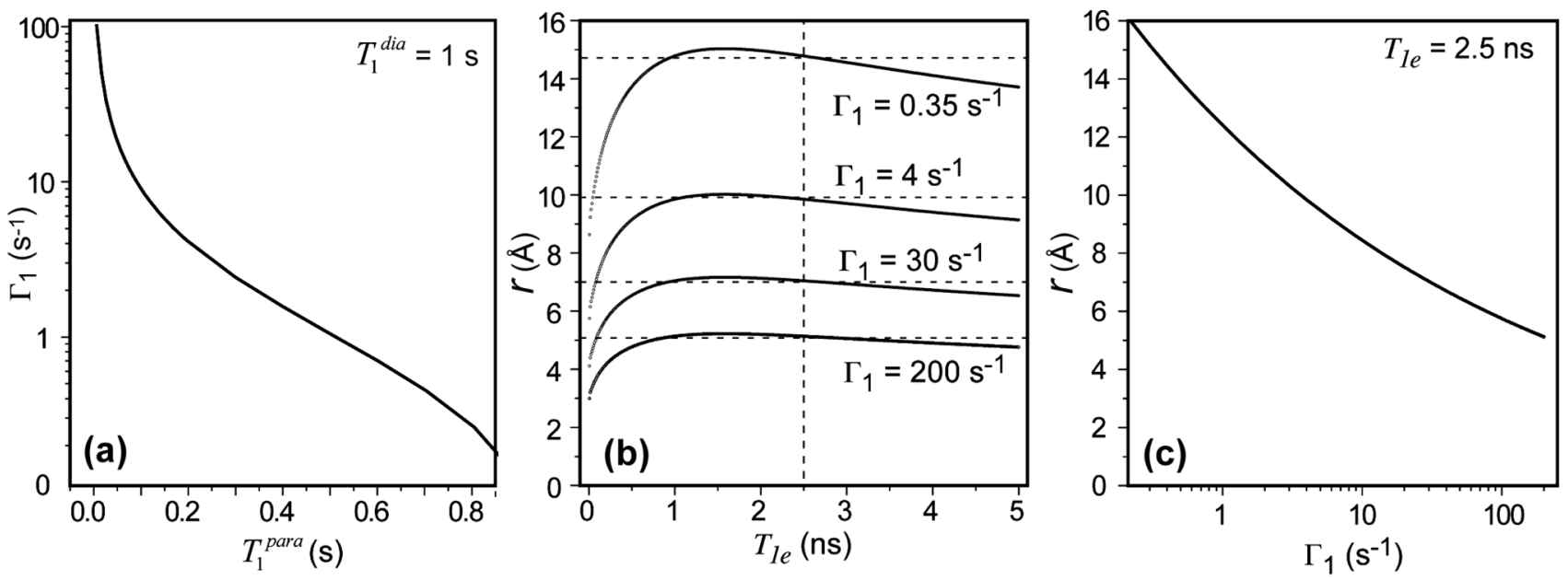

Figure 1.

Distance extraction from $\mathrm{Cu}(\mathrm{II})$-induced ${ }^{13} \mathrm{C} \mathrm{T}_{1}$ PRE. (a) Dependence of $\Gamma_{1}$ on $T_{1}^{\text {para }}$, assuming a diamagnetic $\mathrm{T}_{1}$ of $1.0 \mathrm{~s}$. (b) ${ }^{13} \mathrm{C}-\mathrm{Cu}$ (II) distances as a function of $\mathrm{T}_{1 \mathrm{e}}$ for different $\Gamma_{1}$. The distances are insensitive to $T_{1 \mathrm{e}}$ for $\mathrm{T}_{1 \mathrm{e}}>1 \mathrm{~ns}$. (c) Distances as a function of $\Gamma_{1}$ for $T_{1 \mathrm{e}}=2.5 \mathrm{~ns}$. 
(a)

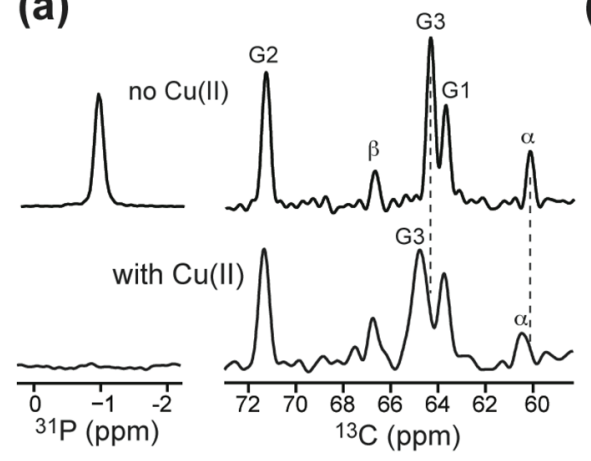

(b)

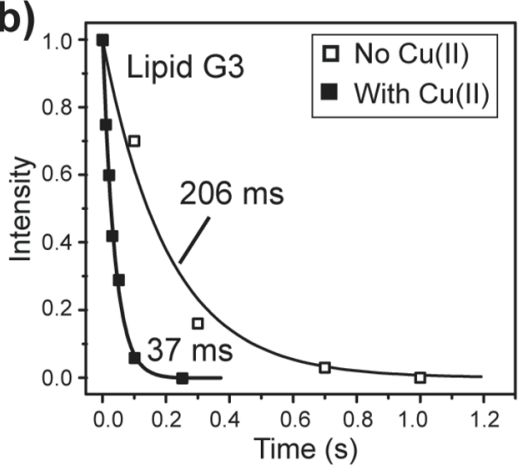

(c)

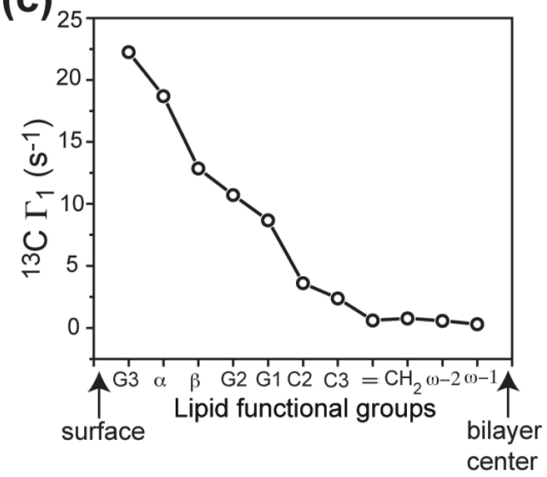

Figure 2.

Effects of $\mathrm{Cu}(\mathrm{II})$ binding on the NMR spectra of POPC bilayers. (a) ${ }^{31} \mathrm{P}$ and ${ }^{13} \mathrm{C}$ spectra without (top) and with (bottom) $\mathrm{Cu}$ (II) at the 1: $15 \mathrm{Cu}$ (II): lipid molar ratio. The ${ }^{31} \mathrm{P}$ signal is quenched by $\mathrm{T}_{2}$ PRE and the glycerol and headgroup ${ }^{13} \mathrm{C}$ signals show line broadening and small pseudocontact shifts for $\mathrm{G} 3$ and $\mathrm{Ca}$. (b) ${ }^{13} \mathrm{C} \mathrm{T}_{1}$ relaxation curves of $\mathrm{G} 3$. (c) ${ }^{13} \mathrm{C} \mathrm{T}_{1}$ PRE for lipid functional groups from the bilayer surface to bilayer center, showing monotonically decreasing $\Gamma_{1}$. 

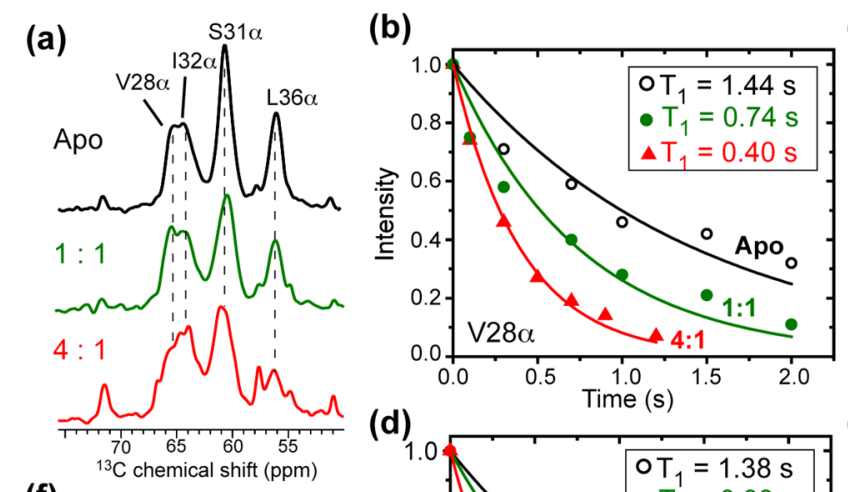

(c)
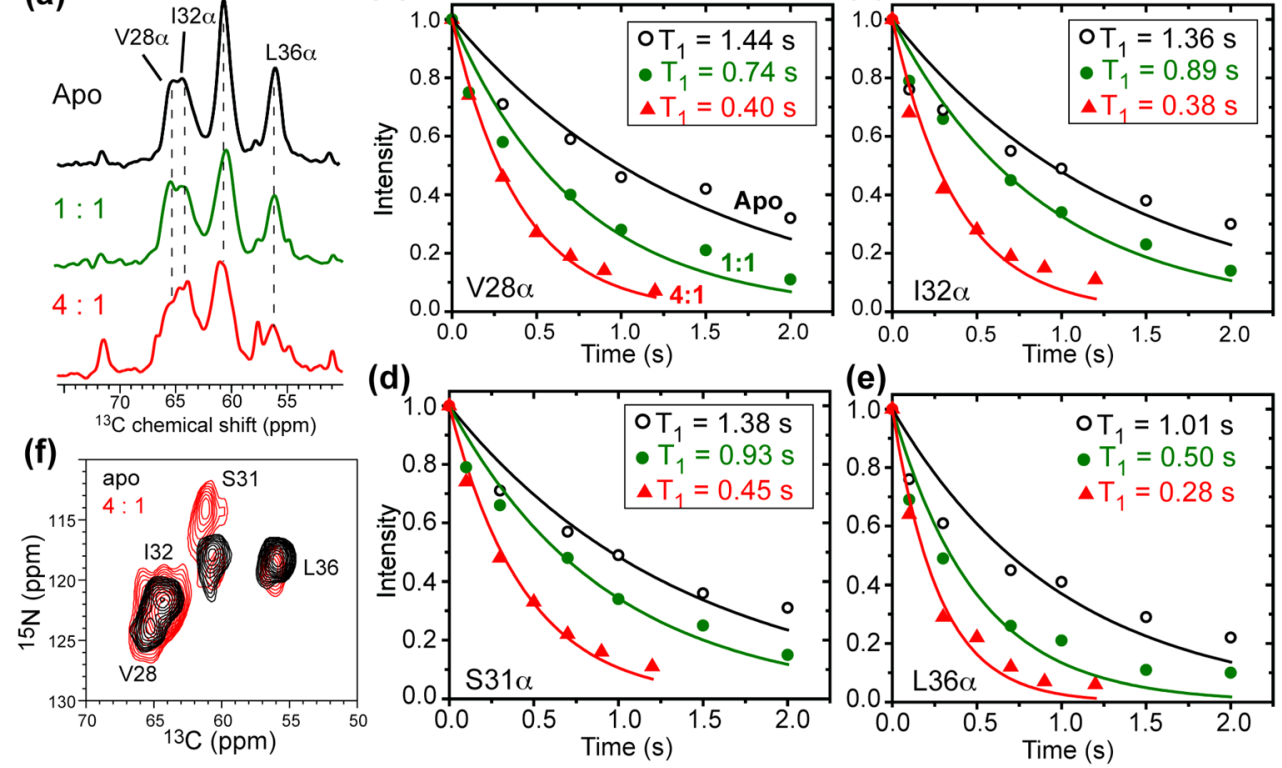

Figure 3.

Effects of $\mathrm{Cu}(\mathrm{II})$ binding on the chemical shifts and ${ }^{13} \mathrm{C} \mathrm{T}_{1}$ relaxation of VSIL-M2TM in the $\mathrm{VM}+$ membrane. (a) ${ }^{13} \mathrm{C}$ spectra in the absence (black) and presence of $\mathrm{Cu}$ (II) at 1:1 (green) and 4:1 (red) $\mathrm{Cu}$ (II): tetramer ratios. Leu36 showed the strongest line broadening (also see Fig. S2). (b-e) Representative ${ }^{13} \mathrm{C} \mathrm{T}_{1}$ relaxation curves for the apo, 1:1, and 4:1 samples. (b) Val28 Ca. (c) Ile32 Ca. (d) Ser31 Ca. (e) Leu36 Ca. (f) $2 \mathrm{D}{ }^{15} \mathrm{~N}-{ }^{13} \mathrm{C}$ correlation spectra of apo and 4:1 Cu(II)-bound VSIL-M2TM samples. Ser31 exhibits a clear ${ }^{15} \mathrm{~N}$ chemical shift change. 


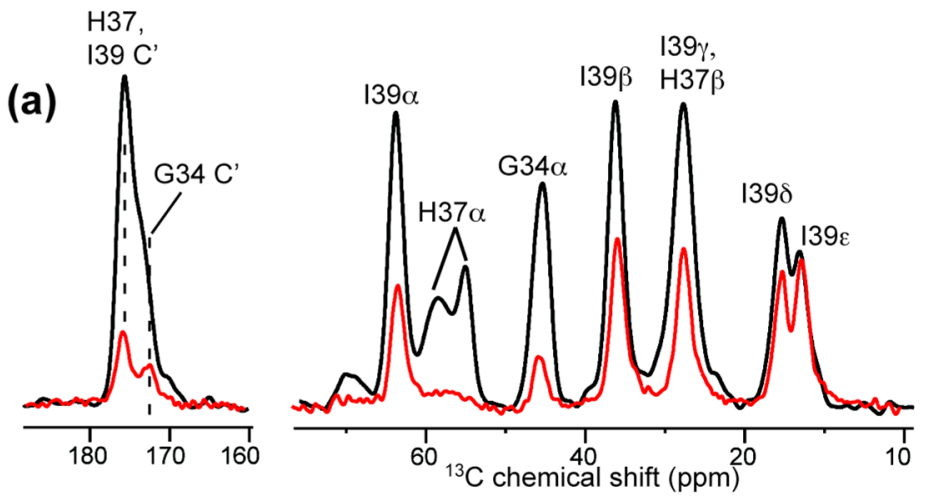

(c)
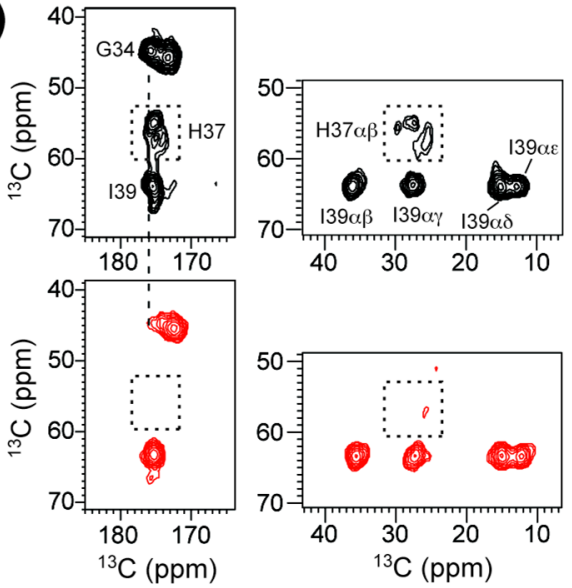

(b)

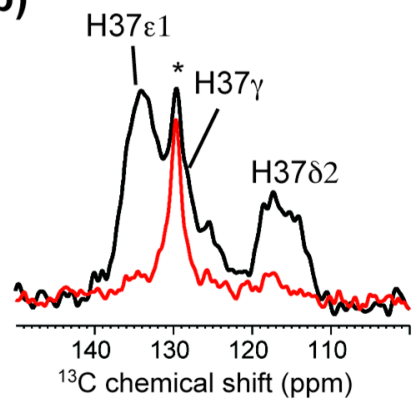

Figure 4.

${ }^{13} \mathrm{C}$ and ${ }^{15} \mathrm{~N}$ MAS spectra of GHI-M2TM in the VM+ membrane without $\mathrm{Cu}(\mathrm{II})$ (black) and with $\mathrm{Cu}$ (II) at the $4: 1 \mathrm{Cu}$ (II): tetramer ratio (red). (a) $1 \mathrm{D}{ }^{13} \mathrm{C}$ double-quantum filtered spectra detecting only peptide signals. The His37 aliphatic and carbonyl signals are mostly suppressed by $\mathrm{Cu}(\mathrm{II})$. (b) Aromatic region of the $1 \mathrm{D}^{13} \mathrm{C}$ MAS spectra with and without $\mathrm{Cu}$ (II). Except for the lipid signal at $130 \mathrm{ppm}$ (denoted by a star), all imidazole signals are suppressed by $\mathrm{Cu}(\mathrm{II})$. (c) Regions of the $2 \mathrm{D}{ }^{13} \mathrm{C}-{ }^{13} \mathrm{C}$ correlation spectra of GHI-M2TM. $\mathrm{Cu}$ (II) binding suppressed the His37 signals and perturbed the Gly34 CO chemical shift. (d) $1{ }^{15} \mathrm{~N}$ MAS spectra. The His37 Ne2 signal is removed while a small fraction $(\sim 10 \%)$ of the N $\delta 1$ intensity remains. The two spectra are scaled such that the N $\delta 1$ intensity is matched to show the preferential suppression of the $\mathrm{N} \varepsilon 2$ peak. No $250-\mathrm{ppm}{ }^{15} \mathrm{~N}$ signal is observed, verifying the acidic $\mathrm{pH}$ of the samples. The $\mathrm{Cu}(\mathrm{II})-\mathrm{N} \varepsilon 2$ chelated imidazole structure is shown in the box. 
(a)

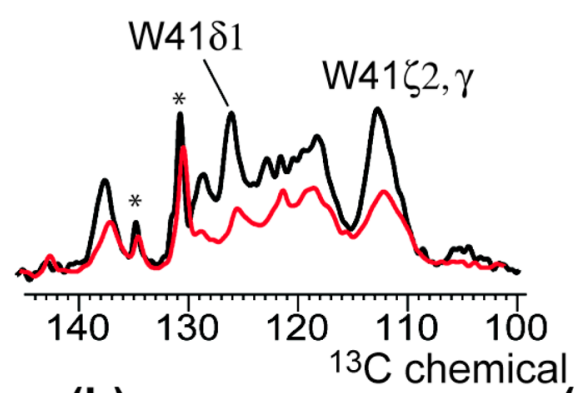

(b)

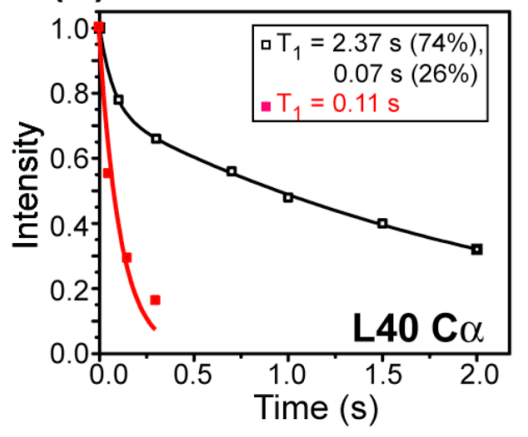

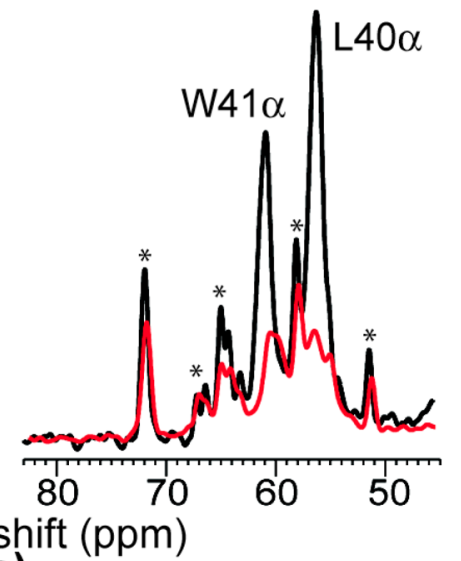

(c)

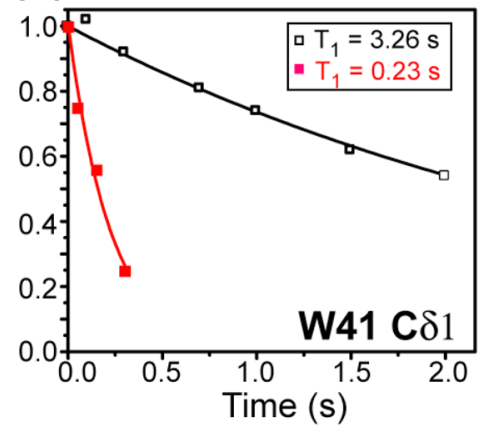

Figure 5.

${ }^{13} \mathrm{C} \mathrm{T}_{1}$ PRE of Leu40 and Trp41 in M2TM. (a) $1 \mathrm{D}{ }^{13} \mathrm{C}$ spectra of LW-M2TM without $\mathrm{Cu}$ (II) (black) and with $\mathrm{Cu}$ (II) at the 4:1 $\mathrm{Cu}$ (II): tetramer ratio (red). Key peptide signals are assigned. Lipid ${ }^{13} \mathrm{C}$ signals are indicated by stars. $(\mathrm{b}-\mathrm{c}){ }^{13} \mathrm{C} \mathrm{T}_{1}$ relaxation curves for Leu 40 $\mathrm{Ca}$ (b) and Trp41 C $\delta 1$ (c). Strong $\mathrm{T}_{1}$ relaxation enhancements are observed, supporting $\mathrm{Cu}$ (II) binding to $\mathrm{Ne} 2$ between His37 and Trp41. A biexponential function was used to fit the Leu40 $\mathrm{Ca}$ decay data due to partial overlap with the lipid $\mathrm{C} \gamma$ peak. 

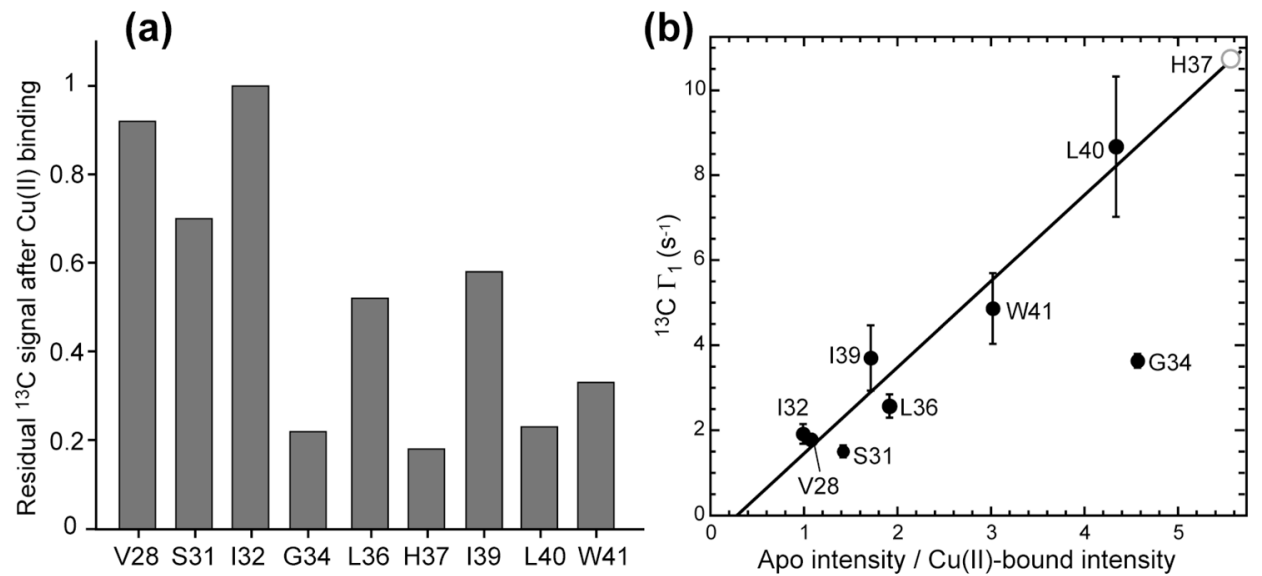

Figure 6.

Correlation between ${ }^{13} \mathrm{C} \mathrm{T}_{1}$ and $\mathrm{T}_{2}$ PRE. (a) $\mathrm{Cu}$ (II) induced reduction of the $\mathrm{Ca}$ intensities of M2TM, reflecting $\mathrm{T}_{2}$ PRE. (b) Correlation between the ${ }^{13} \mathrm{C} \mathrm{T}_{1} \mathrm{PRE}$ and the ${ }^{13} \mathrm{C}$ intensity reduction factor, which is the inverse of the residual intensity plotted in (a). Residues that show large $\mathrm{T}_{1}$ PRE also have large intensity reductions. Gly34 $\mathrm{Ca}$ shows anomalously low intensities (strong $\mathrm{T}_{2} \mathrm{PRE}$ ) because the $\mathrm{CH}_{2} \mathrm{Ca}$ group is more sensitive to ${ }^{1} \mathrm{H}$ quenching by $\mathrm{Cu}$ (II) than the $\mathrm{CH} \mathrm{Ca}$ groups of all other amino acid residues. The His $37 \mathrm{Ca}$ intensity reduction suggests a ${ }^{13} \mathrm{C} \Gamma_{1}$ of $\sim 10 \mathrm{~s}^{-1}$ (open circle). 

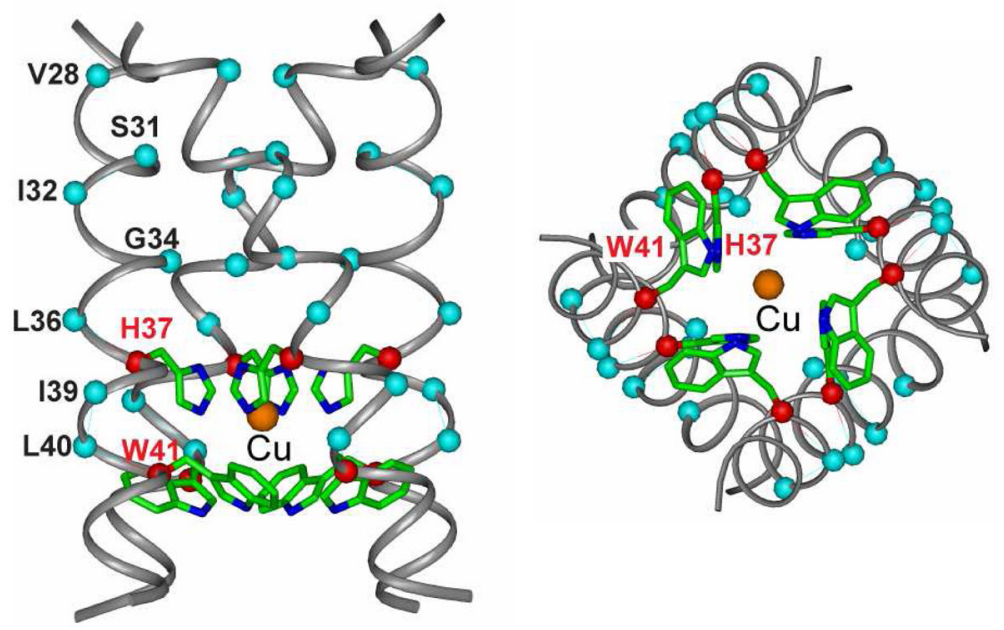

Figure 7.

Proposed model of the $\mathrm{Cu}$ (II) binding site in M2TM. $\mathrm{Cu}$ (II) (orange), bound to the center of the square formed by the $\mathrm{N} \varepsilon 2$ atoms of the His 37 tetrad, is trapped in an aromatic cage formed by the four His 37 imidazolium rings from the top and the four Trp41 indole rings from the bottom, thus explaining the high affinity of the binding and the mechanism of inhibition of proton conduction. 


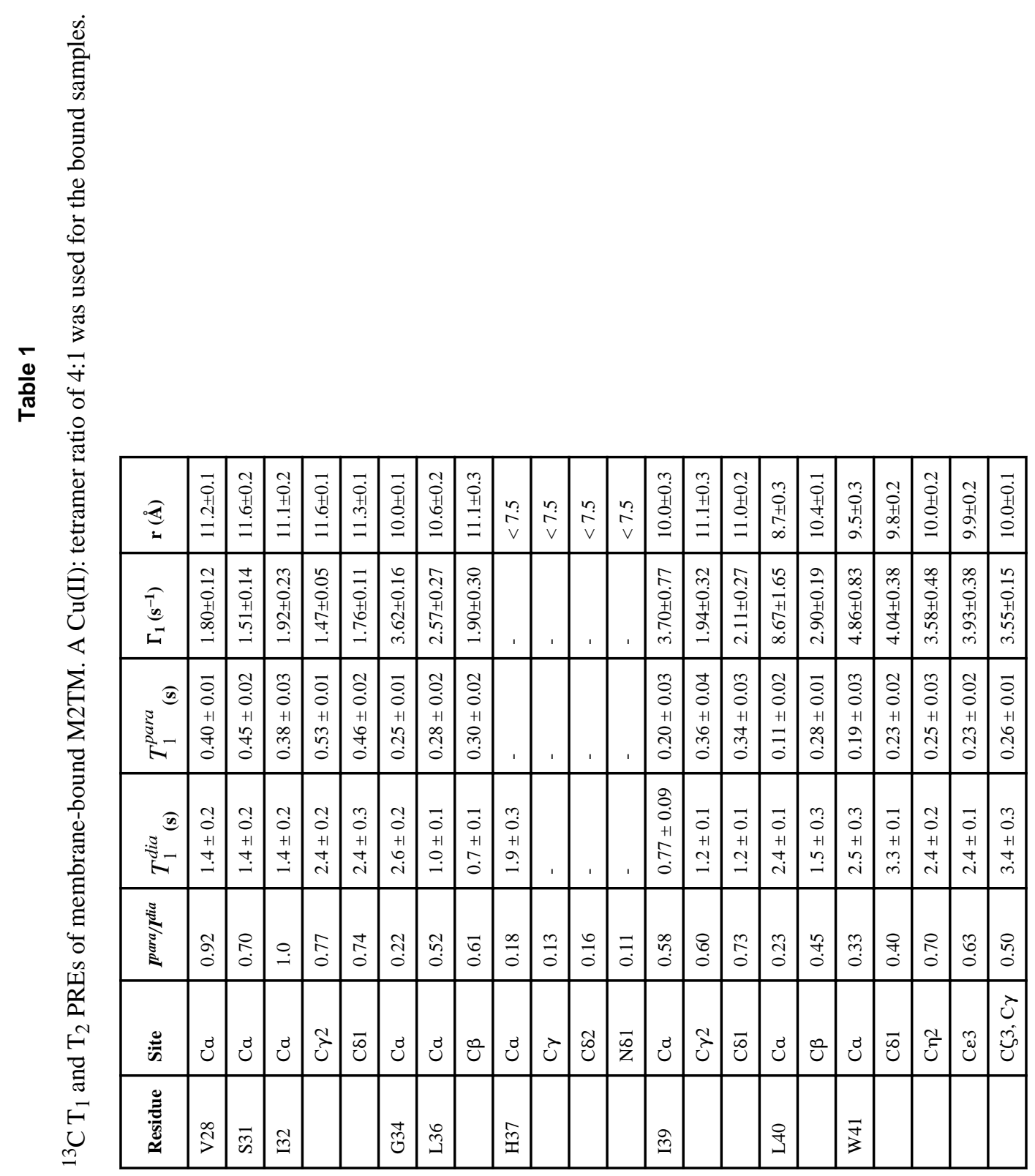

J Am Chem Soc. Author manuscript; available in PMC 2013 May 23. 